\title{
Factors Associated with herb and dietary supplement use by young adults in the United States
}

\author{
Paula Gardiner*†1,4, Kathi J Kemper ${ }^{\dagger 2}$, Anna Legedza ${ }^{\dagger 3}$ and \\ Russell S Phillips ${ }^{\dagger 3}$
}

\begin{abstract}
Address: ${ }^{1}$ Boston University Medical School, Department of Family Medicine, Boston, Massachusetts, USA, ${ }^{2}$ Department of Pediatrics, Public Health Sciences and Family and Community Medicine, Wake Forest University School of Medicine, Winston-Salem, North Carolina, USA, ${ }^{3}$ Division for Research and Education in Complementary and Integrative Medical Therapies, Harvard Medical School, Boston, Massachusetts, USA and ${ }^{4}$ Department of Family Medicine, Boston University Medical Center, 1 Boston Medical Center Place, Dowling 5 South Boston, MA 02118, USA

Email: Paula Gardiner* - pgardine@massmed.org; Kathi J Kemper - kkemper@wfubmc.edu; Anna Legedza - anna@hsph.harvard.edu; Russell S Phillips - rphillips@bidmc.harvard.edu

* Corresponding author †Equal contributors
\end{abstract}

Published: 30 November 2007

BMC Complementary and Alternative Medicine 2007, 7:39 doi:10.1 186/1472-6882-7-39

This article is available from: http://www.biomedcentral.com/l472-6882/7/39

(c) 2007 Gardiner et al; licensee BioMed Central Ltd.

This is an Open Access article distributed under the terms of the Creative Commons Attribution License (http://creativecommons.org/licenses/by/2.0), which permits unrestricted use, distribution, and reproduction in any medium, provided the original work is properly cited.
Received: I June 2007

Accepted: 30 November 2007

\begin{abstract}
Background: Little is known about the association between use of herbs and dietary supplements (HDS) and lifestyle/behavior factors in young adults in the US.

Methods: Analyzing the 2002 National Health Interview Survey (NHIS), we examined the patterns of HDS (excluding vitamins/minerals) use among young adults in the United States using descriptive statistics and logistic regression.

Results: In our sample of 18 to 30 year olds $(n=6666), 26 \%$ were current smokers, $24 \%$ were moderate/heavy drinkers, $43 \%$ had high physical activity, and $54 \%$ and $76 \%$ use prescription and over the counter (OTC) medications respectively. Non-vitamin, non-mineral HDS was used by $17 \%$ of the overall sample in the last 12 months. In the multivariable analysis, the lifestyle and behavioral factors associated with HDS use include: current smoking (odds ratio $1.4 \mathrm{I} 95 \% \mathrm{Cl}$ [I.I6-I.72]); being a former smoker (I.50 [I.I5-I.95]); moderate/heavy alcohol use (2.02 [I.53-2.65]); high physical activity levels (2.45 [I.98-3.03]); and prescription medication use (I.5 I [I.26-I.8I]). Among HDS users, only $24 \%$ discussed their use with a health care professional.
\end{abstract}

Conclusion: Nearly one in five young adults report using non-vitamin/non-mineral HDS.

\section{Background}

According to the National Institute of Health's Office of Dietary Supplements, a dietary supplement is intended to supplement the diet; and contains one or more dietary ingredients (including vitamins; minerals; herbs or other botanicals; amino acids; and other substances) or their constituents [1]. Many American adults use vitamins, minerals, botanicals, and other dietary supplements on a regular basis [1-4]. Analyses of the National Health Interview Survey (NHIS) have estimated 10 to 19 percent of the U.S. population uses a non-vitamin/mineral herb or dietary supplement (HDS) for health conditions [5-8].

Although rates of dietary supplement use vary by age, gender, race, and ethnicity, very little is known about the pattern of use among college age and young adults. Young 
adults are known to engage in high risk behaviors such as alcohol and tobacco use. Using certain dietary supplements, such as high dose ephedra product in a weight loss products or sport performance products is also a high risk behavior. Little is known about the correlation between high risk dietary supplements (stimulants or depressants) and other young adult's behavior.

Surveys of college athletes, college students, and young adults have demonstrated a strong link between high physical activity and use of sport supplements to enhance athletic performance [9-15]. Although this trend has been seen in special populations (i.e., athletes); it has not been replicated in a general population of young adults [9-15].

Higher rates of HDS use have also been reported among patients using prescription and non-prescription medications in pediatric and adult surveys [3]. This use is particularly concerning due to the potential for herbmedication interactions. This relationship has not been specifically evaluated in the young adult population.

Communication with health professionals about HDS use has been reported by fewer than half of adult and pediatric patients who use them $[2,16,17]$. This relationship has not been explored in the young adult population, but could have important implications for health care in this group.

Using data from NHIS, we examined the overall prevalence and patterns of HDS use among young adults and the prevalence of specific HDS use with lifestyle/behavioral factors such as: alcohol use, tobacco use, high physical activity, or medication use. Finally we explored disclosure rates of HDS use to health care professionals. We hypothesized that young adults would use HDS about as often as other age groups; that those engaging in high risk behaviors (alcohol and tobacco use) and athletes use HDS more often than those who do not smoke, drink alcohol or exercise regularly; that use would be higher among those using prescription and non-prescription medications. Finally, we hypothesized that fewer than half of young adults using HDS would discuss this use with a health professional.

\section{Methods}

Previously we have described our methods of analysis $[2,3]$. We analyzed data from the Sample Core component and the Alternative Health Supplement to the 2002 National Health Interview Survey (NHIS). The NHIS is an in-person household survey conducted by the Census Bureau for the National Center for Health Statistics, and is the principal source of information in the U.S. on the health of the civilian, non-institutionalized household population. One adult was randomly selected from each household to complete this portion of the survey. There were 31,044 completed interviews, with a $73.4 \%$ response rate. The sampling methods for the NHIS are described elsewhere [18].

For the NHIS, respondents were specifically asked, "Some people use natural herbs for a variety of health reasons. Some people drink an herbal tea to remedy a flu or cold. Others take a daily pill to help with a health condition or just stay healthy. Have you ever used natural herbs for your own health or treatment (for example ginger, echinacea or black cohosh including teas, tinctures, and pills) [18]?" Those respondents that said yes were asked "During the past 12 months, did you use natural herbs for your own health or treatment?" For the purpose of this analysis, we will refer to any herb use as having occurred in the prior 12 months. Of those that said yes to this question, respondents were asked a series of questions about individual HDS use and disclosure of that use to conventional health care providers.

Because we were interested in high risk HDS behaviors, we excluded use of vitamins and minerals (which may have been recommended by health professionals), and focused on non-vitamin/mineral supplements. Respondents chose from a list of 35 non-vitamin/mineral supplements dietary supplements (29 supplements were plant based and 6 supplements not plant based these included: s-adenosylmethionine (SAM-e) progesterone cream, melatonin, bee pollen, fish oil, glucosamine and chondroitin).

We defined a young adult age range between 18 years of age to 30 years of age based on education and earning potential. We considered socio-demographic factors including respondents' age $(18-22,23-30)$ gender, education (<high school, high school graduate, some college, college graduate), annual family income $(<\$ 15,000$, $\$ 15,000-34,999, \$ 35,000-64,999, \geq \$ 65,000)$, race/ethnicity (Hispanic, non-Hispanic white, non-Hispanic black non-Hispanic other (Asian, American Indian/Alaskan native, Asian Indian, Chinese, and Filipino) and region of U.S. residence (Northeast, Midwest, South, West).

We also included lifestyle/behavioral factors that we thought could interact with or cause adverse events with HDS. These included smoking (current, former, nonsmoker); alcohol use in the past 12 months (abstainer or former drinker, current infrequent or light drinker $(<3$ drinks a week), current moderate to heavy ( $>3$ drinks per week to $>14$ drinks a week), or unknown drinking status);

Although physical activity level, in itself, is not a high risk behavior, adolescent and adult athletes have been reported to use herbs and other performance enhancing supplements more frequently than others of their age 
groups. Therefore, we analyzed a physical activity level variable [high (vigorous activity 2 times/wk or moderate activity 4 times/wk), moderate (vigorous activity 1 time/ wk or moderate activity 1-3 times/wk), or sedentary (no vigorous or moderate activity/week)] in the model to assess for an association high physical activity with HDS in a national population of youth [19].

Respondents were asked if they used prescription and over the counter (OTC) medications in the last 12 months. Respondents were asked if they disclosed natural herb use to conventional medical professionals including physicians, nurse practitioners, physician assistants, psychiatrists, and dentists.

Population estimates were calculated using NHIS weights, which are calibrated to U.S. 2000 census totals for gender, age, and race/ethnicity of the 2002 U.S. population. Descriptive statistics were used to examine the prevalence of HDS use, the most common HDS used among smokers and alcohol drinkers, and disclosure to medical professionals. We used multivariate logistic regression analysis to assess which variables were significantly associated with HDS use. We selected lifestyle and behavioral variables for testing in our logistic model adjusting for age, sex, race, income, education and entered these variables into the final model simultaneously. All analyses were performed using SAS- callable SUDAAN version 8.1 (Research Triangle Institute, Research Triangle Park, NC) [20] to account for the complex sampling design of the NHIS.

\section{Results}

Of the total 31,044 NHIS respondents, 6,666 were ages 18-30; these respondents represented approximately 49 million US young adults in 2002. The majority of young adult respondents were non-Hispanic white (64\%) and age $24-30(60 \%) ; 40 \%$ had some college experience and $19 \%$ had a college degree. (Table 1 ) Twenty six percent of young adults were current smokers, 32\% used no alcohol, $44 \%$ were infrequent/light drinkers and $21 \%$ were moderate/heavy drinkers. Thirty four percent had low physical activity, 22\% had moderate activity, and $43 \%$ had high physical activity levels. Fifty four percent used a prescription medication and $76 \%$ used an OTC medication in the last year.

Of the respondents, $17 \%$ (extrapolated for the U.S. adult population to 8.4 million) reported having used a nonvitamin, non-mineral HDS in the last 12 months. Demographic factors associated with higher HDS use included (Table 1): being older, having a higher income, having a college education and being Non-Hispanic others (Asian, American Indian/Alaskan native, Asian Indian, Chinese, and Filipino). The HDS most commonly used were echi-
Table I: Demographics of Respondents Ages 18 to 30 years and the Percent of Characteristics by Individual Variables Among Those Who Use HDS

\begin{tabular}{lccc}
\hline Characteristics & Total Respondents & HDS user** \\
I8-30 $(\mathrm{N}=6666) \%$ & $\mathrm{P} * * * 1|7|) \%$
\end{tabular}$\quad$

\begin{tabular}{|c|c|c|c|}
\hline \multicolumn{4}{|l|}{$\begin{array}{l}\text { Socio-demographic } \\
\text { variables }\end{array}$} \\
\hline \multicolumn{3}{|l|}{ Age, yr } & \multirow[t]{3}{*}{$<.01$} \\
\hline $18-22$ & 40 & 15 & \\
\hline $23-30$ & 60 & 19 & \\
\hline \multicolumn{3}{|l|}{ Sex } & \multirow[t]{3}{*}{.12} \\
\hline Male & 49 & 16 & \\
\hline Female & 51 & 18 & \\
\hline \multicolumn{3}{|l|}{ Race/Ethnicity } & \multirow[t]{6}{*}{$<.01$} \\
\hline Non-Hispanic White & 64 & 19 & \\
\hline Non-Hispanic Black & 14 & 13 & \\
\hline Non-Hispanic Asian & 5 & 17 & \\
\hline Non-Hispanic Other*** & I & 27 & \\
\hline Hispanic & 16 & 12 & \\
\hline \multicolumn{3}{|l|}{ Education Level } & \multirow[t]{5}{*}{$<.01$} \\
\hline$<$ High School & 16 & 7 & \\
\hline High School Grad & 24 & 15 & \\
\hline Some College & 40 & 19 & \\
\hline College Graduate & 19 & 25 & \\
\hline \multicolumn{3}{|l|}{ Income, $\$$} & \multirow[t]{6}{*}{$<.01$} \\
\hline$<15,000$ & 26 & 18 & \\
\hline $15,000-34,999$ & 24 & 21 & \\
\hline $35,000-64,999$ & 10 & 23 & \\
\hline$\geq 65,000$ & 2 & 30 & \\
\hline Did not reply & 38 & 12 & \\
\hline \multicolumn{4}{|l|}{$\begin{array}{l}\text { Lifestyle/behavioral } \\
\text { variables }\end{array}$} \\
\hline \multicolumn{3}{|l|}{ Smoking Status } & \multirow[t]{4}{*}{$<.01$} \\
\hline Current & 26 & 21 & \\
\hline Former & 9 & 24 & \\
\hline Never & 63 & 15 & \\
\hline \multicolumn{3}{|l|}{$\begin{array}{l}\text { Alcohol use in last } 12 \\
\text { months }\end{array}$} & \multirow[t]{5}{*}{$<.01$} \\
\hline None & 32 & 9 & \\
\hline Infrequent/light & 44 & 21 & \\
\hline Moderate/heavy & 21 & 24 & \\
\hline $\begin{array}{l}\text { Unknown drinking } \\
\text { status }\end{array}$ & 3 & 5 & \\
\hline \multicolumn{3}{|l|}{ Physical Activity } & \multirow[t]{5}{*}{$<.01$} \\
\hline Low & 34 & 9 & \\
\hline Moderate & 22 & 19 & \\
\hline High & 43 & 23 & \\
\hline Unknown & 2 & 6 & \\
\hline \multicolumn{3}{|l|}{$\begin{array}{l}\text { Prescription medication } \\
\text { use }\end{array}$} & \multirow[t]{3}{*}{$<.01$} \\
\hline Yes & 54 & 22 & \\
\hline No & 46 & 13 & \\
\hline \multicolumn{3}{|l|}{$\begin{array}{l}\text { Over the counter } \\
\text { medication use }\end{array}$} & \multirow[t]{3}{*}{$<.01$} \\
\hline Yes & 76 & 19 & \\
\hline No & 24 & 12 & \\
\hline \multicolumn{4}{|c|}{$\begin{array}{l}\text { * "DURING THE PAST I } 2 \text { MONTHS, did you use herbs for your own } \\
\text { health or treatment ?" } \\
\text { ** Chi Square test comparing HDS users to non-HDS users }(P<.05) \\
\text { *** (Asian, American Indian/Alaskan native, Asian Indian, Chinese and } \\
\text { Filipino) } \\
\text { ****Data sources National health interview survey } 2002, \text { weighted } \\
\text { percents extrapolated from the to the U.S. census }(2000) \text { for the adult } \\
\text { civilian, non-institutionalized household population. }\end{array}$} \\
\hline
\end{tabular}


nacea (used by $45 \%$ of HDS users), ginseng (34\%), ginkgo biloba (22\%), garlic (15\%), St. Johns wort (14\%), peppermint (14\%), ginger (10\%), chamomile, (9\%), kava kava (9\%), and ephedra (7\%). The most common conditions for which HDS were used were for were head or chest cold, (reported by $40 \%$ of HDS users), stomach or intestinal conditions (12\%), musculoskeletal conditions $(10 \%)$, severe headache or migraine $(8 \%)$, anxiety of depression (7\%), and insomnia (6\%).

High risk behaviors (current smoking and moderate/ heavy drinking) were positively associated with HDS use. For example, rates of HDS use were 24\% among former smokers, $21 \%$ among current smokers, and 15\% in nonsmokers. Rates of HDS use were $24 \%$ among moderate/ heavy drinkers, compared with $9 \%$ in non-drinkers. Compared to non smokers, smokers used significantly more ginseng, gingko, and St. Johns wort $(\mathrm{p}<.001)$. Compared to non drinkers, moderate/heavy drinkers used significantly more ginseng, chamomile ( $\mathrm{p}<.001$ for each comparison), Echinacea $(\mathrm{p}=.04)$ and gingko biloba $(\mathrm{p}=.01)$ (Table 2).

The prevalence of HDS use was 23\% for those with high physical activity, compared with for 9\% low physical activity. Respondents with high physical activity used more stimulant herbs in particular (Table 2).

Use was also significantly higher among those who used prescription medications (22\%) and OTC medications (18\%), than among those use used neither $(\sim 13 \%, \mathrm{P}<.01$ for each comparison). Compared to non-prescription medication users, prescription medication users took more garlic $(\mathrm{p}=.03)$ and those who took OTCs used more echinacea $(\mathrm{p}=.001)$.

\section{Multivariable Analysis of Characteristics Associated with HDS Use}

In the multivariable analysis, after adjusting for age, sex, race, income, and education, the factors associated with HDS use included: current smoking (odds ratio $1.4195 \%$ CI [1.16-1.72]) former smoking (1.50 [1.15-1.95]), moderate/heavy alcohol use (2.02 [1.53-2.65]), high activity levels (2.45 [1.98-3.03]) and prescription medication use (1.51 [1.26-1.81]). OTC medication use was not associated independently with HDS use (Table 3).

\section{Disclosure of HDS use to health professionals}

Only $24 \%$ of those who reported using HDS disclosed their herb use to a health professional; $67 \%$ did not disclose their use, with $10 \%$ noting they did not go or talk to a conventional professional in the last 12 months. Disclosure was slightly less common among heavy drinkers than non-drinkers (18\% versus $21 \%, \mathrm{P}=0.06$ ), but similar among smokers and non-smokers and those with different activity levels. Disclosure was more common among prescription medication users than non-users (30\% versus $11 \%, \mathrm{P}<0.001)$; it was also more common among OTC medication users compared to non- users (25\% versus $17 \% \mathrm{P}=0.02$ )

\section{Discussion}

Based on these data, an estimated 8 million young adults in the U.S. used a non-vitamin/mineral HDS during the prior 12 months. Use in this age group is substantial and not lower than rates in other age groups $[4,5,21]$. As expected, use was significantly higher among smokers, those who consume alcohol, those who reported high levels of exercise, and those who used prescription medications [22,23]. Only 24\% discussed their HDS with a health care professional, a rate even lower than that seen in older adult and younger pediatric populations.

Table 2: Prevalence of Specific HDS Supplement Use Among Young Adults who use Alcohol and Tobacco

\begin{tabular}{|c|c|c|c|c|c|c|}
\hline \multirow[b]{2}{*}{ Dietary Supplement } & \multicolumn{3}{|c|}{ High Risk Lifestyle factors } & \multicolumn{3}{|c|}{ Other Lifestyle factors } \\
\hline & $\begin{array}{l}\text { Smoker } \\
N=362 \%\end{array}$ & $P$ & $\begin{array}{l}\text { Alcohol Moderate/heavy } \\
\qquad \mathrm{n}=335 \%\end{array}$ & $P$ & $\begin{array}{l}\text { High Physical activity } \\
\qquad N=662 \%\end{array}$ & $P$ \\
\hline Echinacea & 40 & .18 & 49 & .02 & 47 & .002 \\
\hline Ginseng & 42 & .03 & 44 & $<.001$ & 37 & $<.001$ \\
\hline Gingko biloba & 29 & .02 & 29 & .01 & 25 & $<.001$ \\
\hline $\begin{array}{l}\text { Sedating herbs valerian, melatonin, } \\
\text { chamomile, kava kava }\end{array}$ & 27 & .02 & 28 & $<.001$ & 21 & .13 \\
\hline Garlic & 17 & .43 & 16 & .54 & 17 & .12 \\
\hline Peppermint & 14 & .79 & 12 & .58 & 16 & $<.001$ \\
\hline St. John's wort & 20 & $<.001$ & 17 & .48 & 15 & .03 \\
\hline Ginger & 8 & .09 & 9 & .57 & 12 & .03 \\
\hline Stimulant herbs ephedra, guarana & 11 & $<.75$ & 13 & $<.001$ & 12 & .005 \\
\hline
\end{tabular}

Data sources National health interview survey 2002, weighted percents extrapolated from the to the U.S. census (2000) for the adult civilian, noninstitutionalized household population. 
Table 3: Independent Effects of Smoking, Alcohol use, Physical Activity, and Medication use on HDS use in Young Adults; Multivariate Logistic Regression

\begin{tabular}{lc}
\hline Lifestyle/behavioral variables & $\begin{array}{c}\text { Adjusted Odds Ratios } \\
\text { [95\% confidence interval] } * *\end{array}$ \\
\hline $\begin{array}{l}\text { Smoking Status } \\
\text { Never }\end{array}$ & 1.0 \\
$\quad$ Current & $1.41[1.16-1.72]$ \\
Former & $1.50[1.15-1.95]$ \\
Alcohol use in last 12 months & 1.0 \\
$\quad$ None & $1.71[1.38-2.13]$ \\
Infrequent/light & $2.02[1.53-2.65]$ \\
Moderate/heavy & 1.0 \\
Physical Activity & $1.88[1.48-2.38]$ \\
Low & $2.45[1.98-3.03]$ \\
Moderate & 1.0 \\
High & $1.51[1.26-1.81]$ \\
Prescription medications & \\
No & 1.0 \\
Yes & $1.13[.91-1.40]$ \\
Over the counter medications & \\
No & \\
Yes &
\end{tabular}

*Logistic Model adjusted for age, sex, race, income, education **Total sample size for analysis 6375 , variables unknown drinking status $(n=225)$ and unknown physical activity $(n=97)$ were excluded from final analysis due to small sample size. A sensitivity analysis with the variables included showed no difference in outcomes. ****Data sources National health interview survey 2002, weighted percents extrapolated from the to the U.S. census (2000) for the adult civilian, non-institutionalized household population.

Previous studies have reported higher rates of HDS among college and university students with a prevalence ranging from of $26 \%$ to $79 \%$ [24-27]. These studies were restricted to single institutions with homogeneous populations; they also used different time periods of HDS use and used a different list of HDS [24-27]. Our rates may have been lower due to the omission of some HDS that are commonly used by athletes; for example, sport drinks, protein powders and body-building hormones were not included in the NHIS survey questions.

In our analysis, the types of individual herbs used by young adults were consistent with other studies $[26,27]$. Green tea, goldenseal, acidophilus, and aloe were reported as popular in previous studies but not asked about in NHIS [24].

In our multivariable analysis several lifestyle and behavioral factors were associated with HDS use. As in other studies of teenagers and adults, rates of HDS use in young adults are highest among those who are smokers and drinkers $[1,5,22,23,27]$. Further research is necessary to study the relationship between HDS lifestyle factors such as smoking and alcohol use and if other high risk behaviors are associated with specific herbs or supplements.
In our study, respondents with moderate and high physical activity level were more likely to use HDS. Numerous studies have found that adolescents and young adults involved in sports have a high prevalence of use dietary supplements $[9,15,28-32]$. The use of sport supplements is especially concerning due to their questionable safety and efficacy.

This picture becomes more complicated by reports that young adults who are athletes tend to have more alcohol and drug use $[13,14]$. Additionally, an association between anabolic steroid and other illicit drug use and high risk behaviors has been documented $[23,33,34]$. More research is necessary to understand why young athletes use HDS recreationally with alcohol or tobacco, for prevention, or for sport performance.

Among HDS users in our sample, 66\% also used prescription medications and $74 \%$ used an over the counter medication in the prior 12 months. Compared to nonprescription medication users, those who used prescription medications were more likely to use HDS. This trend has been reported in previous surveys of young adults $[24,26]$. Increasing numbers of reports describe clinically serious interactions between prescription drugs and herbals/supplements and concern has grown that the problem of adverse effects may be under reported [35-38].

Among young adult HDS users, the most common conditions associated with use were head or chest cold, stomach or intestinal conditions, musculoskeletal conditions, severe headache or migraine, anxiety of depression, and insomnia. In the general adult population, the most frequent conditions prompting HDS use were upper respiratory infections, depression, musculoskeletal pain, and memory improvement $[4,35]$. Other studies of young adults reported high use for musculoskeletal conditions, depression, weight loss, body building, allergies, gastrointestinal symptoms, and general health improvement [2427].

In our analysis, the prevalence of talking with health professionals about HDS use (24\%) is even lower than that reported in adult and young adults populations (approximately 35 to $44 \%$ ) [5,7,26,39-41]. More research is needed to understand how health care professionals and young adults discuss HDS, what benefits and adverse events young adults experience, and how best to advise them. It is critical that all health care professionals ask and counsel their patients about HDS use. For example, one study of college students, $14 \%$ reported an adverse reaction from an HDS yet $58 \%$ continued to take the supplement despite adverse reactions [26]. 
There are several limitations in our analysis. First, NHIS did not ask respondents about all the different types of dietary supplements used by young adults. Second, the survey is based on self-reported data, thus, subjects may be under or over-reporting their use of herbs. The term "natural herbs" (rather than herbal medications or herbal products) may have been misunderstood by respondents. Respondents who did not use natural herbs, such as sport supplement or weight lose product, may not have disclosed use. The survey listed only 29 herbs although there are thousands of botanicals sold as combination dietary supplements or ethnic traditional medicines in the U.S.

\section{Conclusion}

In conclusion, nearly one in five young adults report using non-vitamin/non-mineral HDS; use is more common among those who smoke, drink alcohol, exercise intensively and among those who use prescription medications. More research is needed to address the safety and efficacy in the young adult population.

For patient safety, health care professionals should be aware that not only are their patients using HDS but the majority of patients are not discussing herb use with them.

\section{Competing interests}

The author(s) declare that they have no competing interests.

\section{Authors' contributions}

PG, KK, RP participated in the design of the study and PG, $\mathrm{AL}$ performed the statistical analysis. All authors read and approved the final manuscript.

\section{Acknowledgements}

Dr. Gardiner is supported by an NIH Institutional National Research Service Award, Grant No. T32-AT005I from the National Center for Complementary and Alternative Medicine (NCCAM) Award K24-AT000589 from NCCAM, National Institutes of Health. Dr. Kemper is supported by NIH grant ROI LM007709 from the NIH National Library of Medicine and by the Fullerton Foundation of Gaffney, South Carolina.

\section{References}

I. Radimer K, Bindewald B, Hughes J, Ervin B, Swanson C, Picciano MF: Dietary supplement use by US adults: data from the National Health and Nutrition Examination Survey, 1999-2000. Am J Epidemiol 2004, I 60(4):339-349.

2. Gardiner P, Graham R, Legedza AT, Ahn AC, Eisenberg DM, Phillips RS: Factors associated with herbal therapy use by adults in the United States. Altern Ther Health Med 2007, I 3(2):22-29.

3. Gardiner P, Graham RE, Legedza A, Eisenberg DM, Phillips RS: Factors Associated With Dietary Supplement Use Among Prescription Medication Users. Arch Intern Med 2006, | 66:1968-1974.

4. Kelly JP, Kaufman DW, Kelley K, Rosenberg L, Anderson TE, Mitchell $A A$ : Recent trends in use of herbal and other natural products. Arch Intern Med 2005, I 65(3):28I-286.

5. Barnes PM, Powell-Griner E, McFann K, Nahin RL: Complementary and alternative medicine use among adults: United States, 2002. Advance Data 2004, 343:1-19.
6. Graham RE, Ahn AC, Davis RB, O'Connor BB, Eisenberg DM, Phillips RS: Use of complementary and alternative medical therapies among racial and ethnic minority adults: results from the 2002 National Health Interview Survey. J Natl Med Assoc 2005, 97(4):535-545.

7. Kennedy J: Herb and supplement use in the US adult population. Clin Ther 2005, 27(I I): I847-1858.

8. $\mathrm{Ni} \mathrm{H}$, Simile $\mathrm{C}$, Hardy AM: Utilization of complementary and alternative medicine by United States adults: results from the 1999 national health interview survey. Medical Care 2002, 40(4):353-358.

9. Calfee R, Fadale P: Popular ergogenic drugs and supplements in young athletes. Pediatrics 2006, I I 7(3):e577-589.

10. Green GA, Uryasz FD, Petr TA, Bray CD: NCAA study of substance use and abuse habits of college student-athletes. Clin J Sport Med 200 I, I I (I):5I-56.

II. Greenwood M, Kreider RB, Melton C, Rasmussen C, Lancaster S, Cantler E, Milnor P, Almada A: Creatine supplementation during college football training does not increase the incidence of cramping or injury. Mol Cell Biochem 2003, 244(I-2):83-88.

12. Herbold NH, Visconti BK, Frates S, Bandini L: Traditional and nontraditional supplement use by collegiate female varsity athletes. Int / Sport Nutr Exerc Metab 2004, I 4(5):586-593.

13. Martens MP, Dams-O'Connor K, Beck NC: A systematic review of college student-athlete drinking: Prevalence rates, sportrelated factors, and interventions. I Subst Abuse Treat 2006, 3 I (3):305-3 I6.

14. Rockafellow BD, Saules KK: Substance use by college students: the role of intrinsic versus extrinsic motivation for athletic involvement. Psychol Addict Behav 2006, 20(3):279-287.

15. Scofield DE, Unruh S: Dietary supplement use among adolescent athletes in central Nebraska and their sources of information. J Strength Cond Res 2006, 20(2):452-455.

16. Hensrud DD, Engle DD, Scheitel SM: Underreporting the use of dietary supplements and nonprescription medications among patients undergoing a periodic health examination. Mayo Clin Proc 1999, 74(5):443-447.

17. Sibinga EM, Ottolini MC, Duggan AK, Wilson MH: Parent-pediatrician communication about complementary and alternative medicine use for children. Clinical Pediatrics 2004, 43(4):367-73.

18. Survey NHI: CAPI Manual for NHIS Field Representatives. 2002:DI.

19. lezzoni L, al E: Mobility impairments and use of screening and preventive services. Am J Public Health 2000, 90(6):955-96I.

20. Professional Software for Survey Data Analysis.

21. Yu SM, Ghandour RM, Huang ZJ: Herbal supplement use among US women, 2000. J Am Med Womens Assoc 2004, 59(I): I7-24.

22. Stephens $M B$, Olsen $C$ : Ergogenic supplements and health risk behaviors. J Fam Pract 200I, 50(8):696-699.

23. Yussman SM, Wilson KM, Klein JD: Herbal products and their association with substance use in adolescents. J Adolesc Health 2006, 38(4):395-400.

24. Ambrose ET, Samuels S: Perception and use of herbals among students and their practitioners in a university setting. Journal of the American Academy of Nurse Practitioners 2004, I 6(4): I 66-73. (23 ref)

25. Johnson SK, Blanchard A: Alternative medicine and herbal use among university students. J Am Coll Health 2006, 55(3): I63-168.

26. Newberry H, Beerman K, Duncan S, McGuire M, Hillers V: Use of nonvitamin, nonmineral dietary supplements among college students. J Am Coll Health 200I, 50(3): I 23-129.

27. Perkin JE, Wilson WJ, Schuster K, Rodriguez J, Allen-Chabot A: Prevalence of nonvitamin, nonmineral supplement usage among university students. Journal of the American Dietetic Association 2002, I 02(3):4l2-4.

28. Dorsch KD, Bell A: Dietary supplement use in adolescents. Curr Opin Pediatr 2005, I 7(5):653-657.

29. Mason MA, Giza M, Clayton L, Lonning J, Wilkerson RD: Use of nutritional supplements by high school football and volleyball players. lowa Orthop J 200 I, 2 I:43-48.

30. McGuine TA, Sullivan JC, Bernhardt DA: Creatine supplementation in Wisconsin high school athletes. Wmj 2002, I 0 I (2):25-30.

31. Metzl JD, Small E, Levine SR, Gershel JC: Creatine use among young athletes. Pediatrics 200I, I 08(2):42I-425. 
32. Stang J, Story MT, Harnack L, Neumark-Sztainer D: Relationships between vitamin and mineral supplement use, dietary intake, and dietary adequacy among adolescents. J Am Diet Assoc 2000, 100(8):905-910.

33. DuRant RH, Middleman AB, Faulkner AH, Emans SJ, Woods ER: Adolescent anabolic-androgenic steroid use, multiple drug use, and high school sports participation. Pediatric Exercise Science 1997, 9(2): 150-8. (27 ref)

34. Middleman $A B$, DuRant RH: Anabolic steroid use and associated health risk behaviours. Sports Med 1996, 2 I (4):25I-255.

35. Kaufman DW, Kelly JP, Rosenberg L, Anderson TE, Mitchell AA: Recent patterns of medication use in the ambulatory adult population of the United States: the Slone survey. Jama 2002, 287(3):337-344.

36. Mills E, Wu P, Johnston BC, Gallicano K, Clarke M, Guyatt G: Natural health product-drug interactions: a systematic review of clinical trials. Ther Drug Monit 2005, 27(5):549-557.

37. Fugh-Berman A, Ernst $E$ : Herb-drug interactions: review and assessment of report reliability. Br J Clin Pharmacol 200I, 52(5):587-595.

38. Ernst E: Herb-drug interactions: potentially important but woefully under-researched. Eur J Clin Pharmacol 2000, 56(8):523-524.

39. Blendon RJ, DesRoches CM, Benson JM, Brodie M, Altman DE: Americans' views on the use and regulation of dietary supplements. Archives of Internal Medicine I6I(6):805- I0. 200I Mar 26

40. Eisenberg DM, Davis RB, Ettner SL, Appel S, Wilkey S, Van Rompay $M$, Kessler RC: Trends in alternative medicine use in the United States, 1990-1997: results of a follow-up national survey.[see comment]. Jama 1998, 280(18): I569-1575.

4I. Leung JM, Dzankic S, Manku K, Yuan S: The prevalence and predictors of the use of alternative medicine in presurgical patients in five California hospitals. Anesth Analg 200I, 93(4): 1062-1068.

\section{Pre-publication history}

The pre-publication history for this paper can be accessed here:

http://www.biomedcentral.com/1472-6882/7/39/prepub

\section{Publish with Biomed Central and every scientist can read your work free of charge}

"BioMed Central will be the most significant development for disseminating the results of biomedical research in our lifetime. "

Sir Paul Nurse, Cancer Research UK

Your research papers will be:

- available free of charge to the entire biomedical community

- peer reviewed and published immediately upon acceptance

- cited in PubMed and archived on PubMed Central

- yours - you keep the copyright 